Supporting Information

\title{
Ag Nanowires Embedded ZnO for Semitransparent Organic Solar Cells with $13.76 \%$ Efficiency and $19.09 \%$ Average Visible Transmittance
}

Lingling Zheng, Ming Li, Shijie Dai, Yinghao Wu, Yuhang Cai, Xinyu Zhu, Shaokun Ma, Daqin Yun* and Jian-Feng $\mathrm{Li}^{*}$

College of Energy, College of Chemistry and Chemical Engineering, Xiamen University, Xiamen 361005, China 

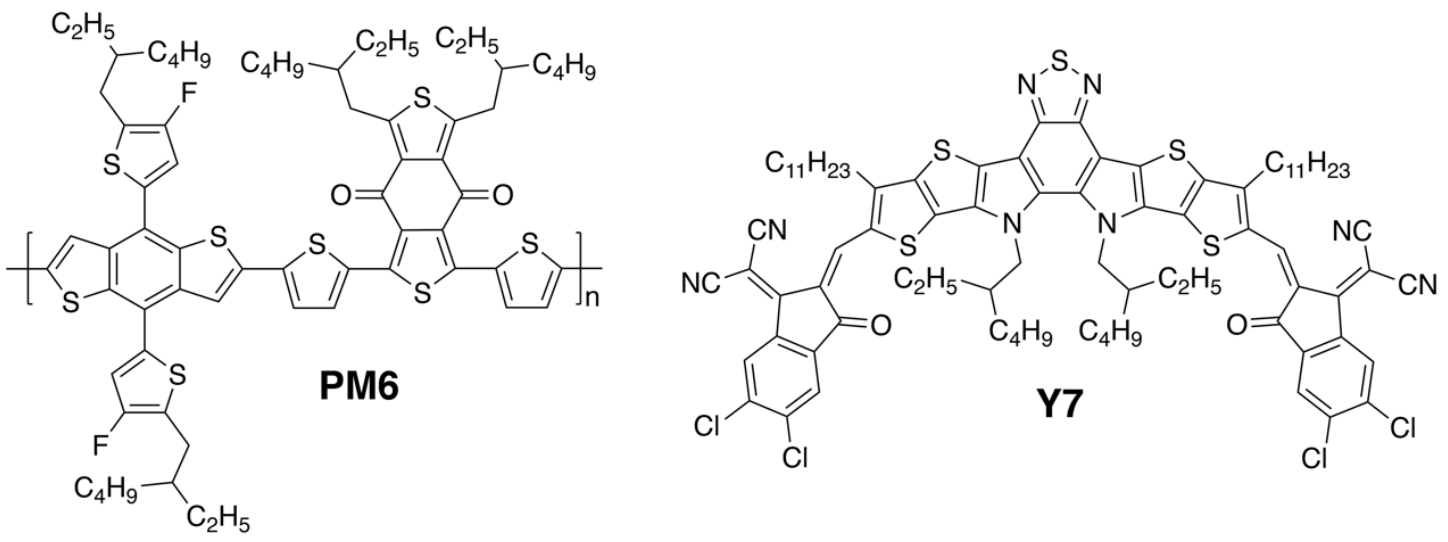

Fig. S1 Molecule structures of PM6 and Y7.

(a)

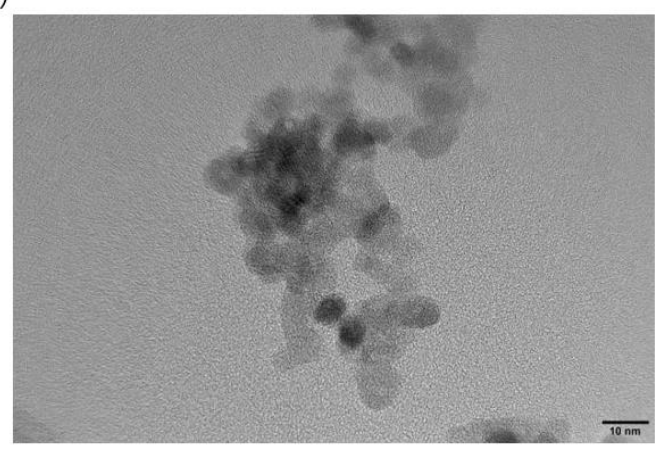

(b)

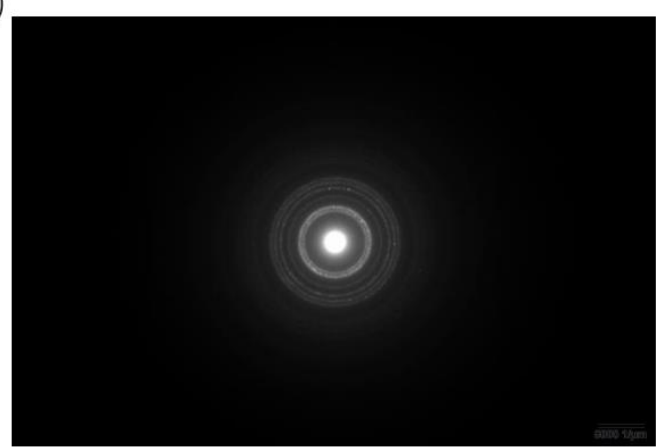

Fig. S2 (a) The high-resolution TEM image of ZnO NPs; (b) the selected area electron diffraction (SAED) pattern of ZnO NPs.

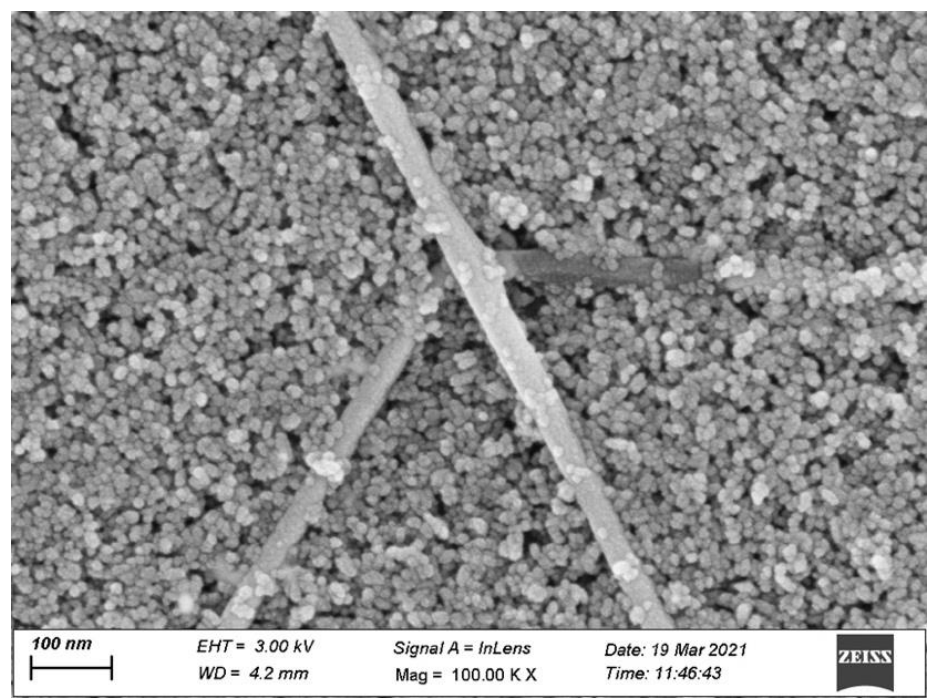

Fig. S3 SEM images of ANZnO film. 

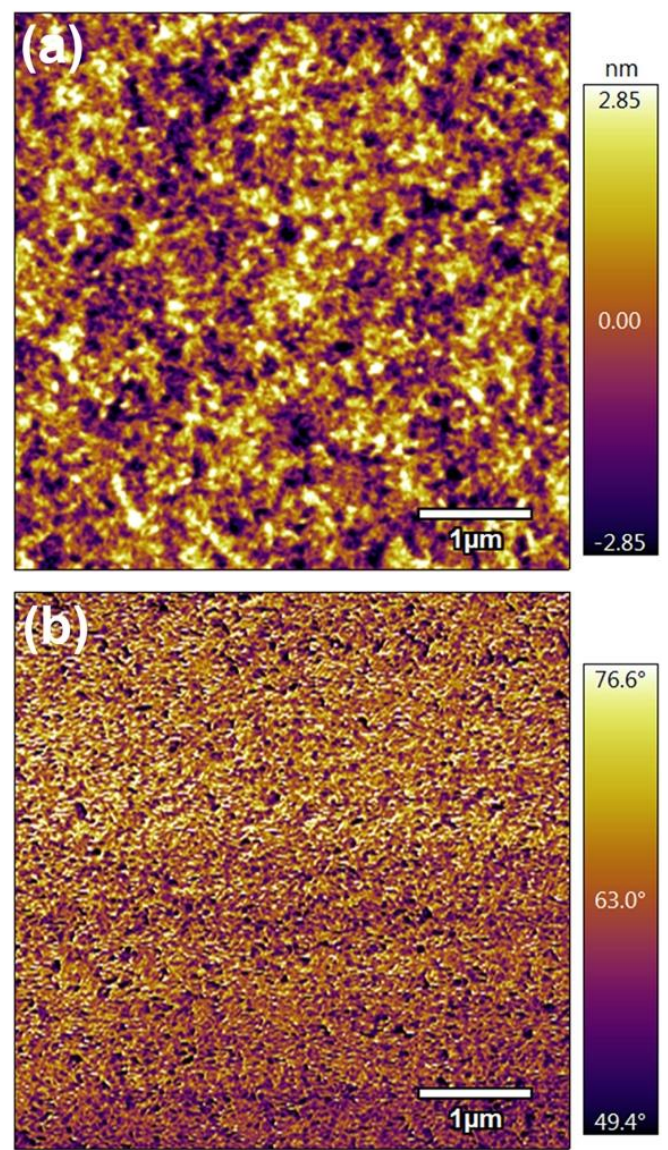

Fig. S4 AFM (a) topographic and (b) phase image of the active layer.

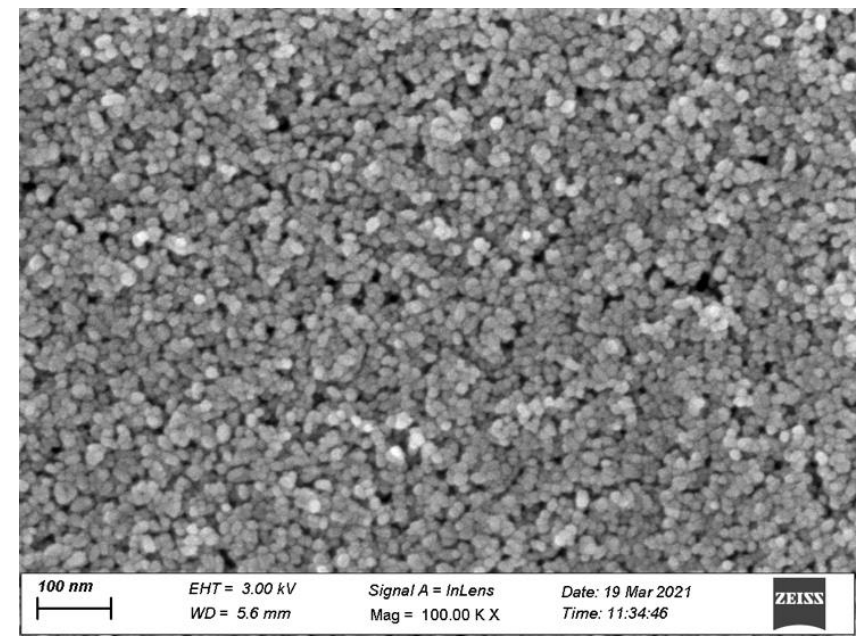

Fig. S5 SEM image of one layer of $\mathrm{ZnO}\left(15 \mathrm{mg} \mathrm{ml}^{-1}\right)$ on the active layer. 